\title{
ENTERPRISE MODELING OF A/E/C FIRM
}

\author{
Ji Sang Park ${ }^{1}$, Teresa M. Adams ${ }^{2}$, Pisun Sirisuksakulchai ${ }^{3}$ \\ ${ }^{1}$ Graduate Research Assistant, University of Wisconsin, Madison,parkji@cae.wisc.edu \\ ${ }^{2}$ Associate Professor, University of Wisconsin, Madison, adams@engr.wisc.edu \\ ${ }^{3}$ Project Engineer, DiCarlo Construction Company, pete@dicarlo.com
}

\begin{abstract}
Dynamic nature of the $\mathrm{A} / \mathrm{E} / \mathrm{C}$ industry, multiple project participant, and disconnected communication between project participants make it difficult to develop integrated information systems for the $\mathrm{A} / \mathrm{E} / \mathrm{C}$ industry. This paper focuses on defining of interrelationship between data model and process model for construction project management, as a step toward fully integrated project management. The paper presents the Information Engineering method for developing an Information Strategy Plan of project management for $\mathrm{A} / \mathrm{E} / \mathrm{C}$ firm, evaluates existing project management software, and uses results of interaction model to identify the best architecture choices for each situation.
\end{abstract}

Keywords: Information Engineering, A/E/C, Enterprise Modeling, System Integration

\section{INTRODUCTION}

The demand for integrated information systems is growing because of globalized-scales of $\mathrm{A} / \mathrm{E} / \mathrm{C}$ projects. $\mathrm{A} / \mathrm{E} / \mathrm{C}$ applications tend to exist independently and have little capacity for communications between them [1]. For example, a company usually has several stand-alone systems to handle its many accounting activities [2].

Jung [3] analyzed corporate level requirements for information systems within a large Korean construction company using five measures for CIC planning, which are corporate strategy, management, computer systems, information technology, incremental investment. In addition, several data models and process models were developed focusing on standard format of information exchange [4][5].

These are due to the unsatisfied information needs that should be considered during the integrated system development phase. Those information needs identified are data accessibility, ability to adapt to changing business needs, data accuracy and consistency, data sharing across organization [6]. In order to achieve those needs, $\mathrm{A} / \mathrm{E} / \mathrm{C}$ business should be reorganized from the top-down perspective.

Enterprise Modeling (EM) is widely used for strategic information system planning [6]. By integrating the collection and processing of information, engineers can gain more systematic insight into the operations they are managing.

The primary objective of this paper is to develop a conceptual process-data model of computer integrated information systems for $\mathrm{A} / \mathrm{E} / \mathrm{C}$ project delivery. The paper illustrates the IE methodology using the IEF CASE tools.

The scope of $\mathrm{A} / \mathrm{E} / \mathrm{C}$ business function is at the project management level of construction and does not involve transactional or worker-level practices. Design and bidding phases for project management are not included. The activities are based on the assumption that project management is the contractor's or construction management team's responsibility.

The data and process models that were developed by a previous study [7], are further extended to include fundamental processes and data for the $\mathrm{A} / \mathrm{E} / \mathrm{C}$ projects. The interaction clustering method is used to identify basic business areas that are the basis for the future subject databases.

\section{INFORMATION ENGINEERING}

Information Engineering (IE) is defined as an interlocking set of format techniques for the planning, analysis, design, and construction of information systems [8]. IE helps to integrate the separate data processing and decision-support systems built by different teams at different times in different places, and seeks to maximize the value of information systems by focusing them on the goals and critical success factors of top management.

Information systems are developed in sequential order with IE: information strategy planning (ISP), business area analysis (BAA), design, and construction [8]. As these phases progress, IE builds a steadily evolving encyclopedia of knowledge about the enterprise, its data models, process models, and system designs. The encyclopedia can be built and modified quickly using automated computer aided systems engineering (CASE) tools.

ISP is applied to an enterprise as a whole for the purpose of identifying business areas and business systems from the top management perspective. ISP is concerned with the goals, critical success factors, strategic systems vision, and the potential impact of technology. It also concerned with data and process modeling as shown in the paper. ISP divides the enterprise into business areas. They are divided by clustering the process-data interaction matrix as shown in the example in this paper. 
BAA is a detailed analysis of business elements that is carried out within a defined business area in preparation for the design of systems to support that area. Reusable data structures, reusable designs, and reusable code are major goals in BAA. They are achieved by identifying common entities and processes and/or subroutines associated with those entities. Since technology is changing rapidly, the systems and procedures used are likely to change, and the enterprise is likely to be reorganized periodically, while the fundamental processes and data remain.

Design concentrates on the design of the business systems and application software to support end-user requirements. A complete and detailed specification of the business systems that are needed to support a defined area within the enterprise is produced. The BAA information is used directly to assist in design. Systems can be designed with the help of automated CASE tools.

Construction of a business system implements the application system design. Major products of this phase are the codes and application of software system; system documentation package; a training package; system operating instructions; an operational database; and the installed application system. Systems can be also constructed with the help of automated CASE tools.

IE analyzes an organization from the enterprisewide approach, and makes it possible to achieve coordination among separately built systems. However, changes in business rules cause changes in the enterprise models. The encyclopedia of goals, data, and functions is meant to be useful for understanding the impact of future system development and modification.

\section{DATA MODELING}

Data modeling begins by identifying subject areas, which are groups of related data entities. After the subject areas have been identified and defined, entity types are identified and entered into the data model.

Table 1 shows the decomposition of project management data by listing subject areas and entity types. The subject areas are Planning, Control, and Completion. Each subject area is broken down into entity types. The entity types in the data decomposition are the fundamental project documents, which are used in the day-to-day project management.

Control Data has several phases of entity types. Project contract, specifications, and subcontract \& subcontract amount are prepared to control contracts. To control resources, human resource control records, material control records, equipment control records, and purchase orders should be created, read, and updated. Accounting and invoicing data include vendor invoices, contract invoices, and applications for payment. To control submittals, request for information, submittal logs, and requests for approval are needed. For controlling change orders, potential change orders, change order requests, subcontract change orders must be prepared. Working drawings $\&$ revisions and shop drawings \& revisions are needed to control drawings. To report current status, project cost report, daily construction report, monthly progress report, and meeting minutes are needed. Furthermore, field productivity report should be included to check current work productivity.

Table 1. Project Management Data Decomposition

\begin{tabular}{ll}
\hline Subject Area & Entity Type \\
\hline Planning & Construction Execution Plan \\
Data & Field Procedure Manual \\
& Detailed Construction Cost Estimate \\
& Project Budget \& Budget Code \\
& Cash Flow Plan \\
& Project Schedule \\
& Resource Management Plan \\
& Organization Chart \\
\hline Control Data & Project Contract \\
& Specifications \\
& Subcontract \& Subcontract Amount \\
& Human Resources Control Records \\
& Material Control Records \\
& Equipment Control Records \\
& Purchase Orders \\
& Vendor Invoices \\
& Contract Invoices \\
& Applications for Payment \\
& Request for Information \\
& Submittal Logs \\
& Requests for Approval \\
& Potential Change Orders \\
& Change Order Requests \\
Subcontract Change Orders \\
Working Drawings \& Revisions \\
Shop Drawings \& Revisions \\
Project Cost Reports \\
Daily Construction Reports \\
Monthly Progress Reports \\
Meeting Minutes \\
Field Productivity Reports \\
\hline As-Built Drawings \\
Final Turnover Documents \\
Certificate of Substantial Completion \\
\hline & \\
Data & \\
& \\
& \\
& \\
& \\
&
\end{tabular}

\section{PROCESS MODELING}

Activity is a generic term for a function or a process. Functions are the necessary activities that must be carried out to ensure the success of the business. Processes are specific activities that support a function [9]. An activity hierarchy is a hierarchical structure of high-level activities that are decomposed into lower-level functions or processes. Each lowerlevel functions and processes can be further decomposed into lower-level processes, until ultimately reaching elementary processes that cannot be further decomposed.

To develop a hierarchy of the project management activities, project-related activities, which are critical 
to achieve project objectives, must be identified. IEF CASE tool is used to draw the activity hierarchy.

Project Management

Project Planning

Cost Plan Development

Develop Detailed Construction Cost

Estimate

Setup Budget Code \& Project Budget Develop Cash Flow Plan

Schedule Development

Resource Management Plan Development

Execution Plan Development

Develop Construction Execution Plan

Develop Field Procedure Manual

Organization Chart Development

Project Control

Start-Up

Award Subcontracts

Define Submittal Log

Approval of Vendor Data

Make Shop Drawings \& Revisions

Submit Request For Information

Log Response to Request For Information

Material \& Equipment Purchasing

Issue Purchase Orders

Record Delivery

Receive \& Verify Vendor's Invoices

Payment to Vendors

Change Orders

Record Proposed Extra Work

Submit Change Orders Request \& Get

Approval

Review Subcontracts' Proposal \& Issue

Change Orders

Subcontracts Payment

Review Invoices

Verify \& Approve Subcontracts' Invoices

Project Payment

Check Cost This Period

Submit Application for Payment

Receive Payment from Owner

Cost \& Resource Control

Keep Labor Records

Keep Material Records

Keep Equipment Records

Develop Project Cost Reports

Indicate Budget Cost Variances

Schedule Control

Check Work Progress

Measure Productivity

File Daily Construction Reports

Develop Monthly Reports

Indicate Schedule Variances

Update Project Schedule

Drawings Management

File Drawings \& Revisions

Revise Shop Drawings

Subcontracts' Meeting \& Meeting Minutes

Management

Seeking Approvals

Project Completion

Punch list Inspection

As-Built Drawings Development

Final Turnover Documents Submitting
Final Acceptance \& Payment

Figure 1. Project Management Activity Hierarchy

Figure 1 shows the activity decomposition of project management. The root function, Project Management, is decomposed into the first-level functions: Project Planning, Project Control, and Project Completion. Then, each first-level function is decomposed into sub-functions. At the lowest level, the functions of project management are decomposed into 43 processes.

For instance, Project Control function focuses on controlling cost, schedule, and quality, and measuring and reporting project progress. This function is decomposed into second level functions: Start-Up, Material/Equipment Purchasing, Change Orders, Subcontractors Payment, Project Payment, Cost/Resource Control, Schedule Control, Drawings Management, Subcontracts' Meeting \& Meeting Minutes Management, and Seeking approvals, which are decomposed into elementary processes. Among them, the main objectives of the Cost/Resource Control function are to keep the costs of ongoing projects within the established budget and to gather information for estimating equipment and labor production rates for other projects [10]. An important tool for cost control is the project cost report which reflects the actual commitments of the project through contracts, purchase orders, change orders, payments, and unforeseen costs.

\section{INTERACTION CLUSTERING}

The process data flow diagram illustrates the flow of processes as well as the input and/or output of the process. Appendix A shows the process data flow diagram for the Cost/Resource Control function. The rounded-boxes are the processes and the squareboxes are the data. Bold arrows are the flow of processes and the normal arrows are the flow of data.

The relationships between activities and data that are shown in the process data flow diagram are used to create the process-data interaction matrix. The matrix shows what data entities are affected by what processes. It also shows which processes share data and which data are required to perform processes. IEF CASE tool is used to develop the interaction matrix.

The result of interaction matrix is rearranged to show a staircase of clusters from top left to bottom right using interaction clustering. Interaction clustering is an automated method for grouping activities that act upon common data objects. Interaction clustering groups closely related activities and data together and identifies affinities among activities through their interactions with data, and affinities among data through their interactions with activities. Clustering are done on create $(\mathrm{C})$, update $(\mathrm{U})$, and read (R) cell values, may or may not be contained in the clustering. The result of interaction clustering is shown in Appendix B. 
The result of interaction clustering is the identification of business areas. Business areas are defined independently of the current organizational structure and information technology. Business areas become the basis for BAA. The business areas that identified in this paper are summarized as follow;

1. Project Organizing organizes the team.

2. Project Estimating prepares detailed cost estimate and sets up budget.

3. Subcontract Management issues Change Orders, controls, and checks subcontracts' activities

4. Vendor Management tracks vendors' activities and payment on their invoices.

5. Budget/Cost Management controls and reports the cost item of the project.

6. Project Scheduling prepares and updates the schedule plans.

7. Submittal Management defines and controls subcontracts' submittals.

8. Resource Management tracks records of material, equipment, and labors.

9. Productivity Management controls day-to-day project productivity.

10. Drawing Management maintains and updates drawings.

11. Project Completion finishes the project after commissioning.

The result of identifying business areas provides a clear understanding of how activities interrelate with data and leads to identification of business systems. Business system is the automated and related manual procedures within an information system that support a set of business processes, such as scheduling, estimating, reporting, cost controlling, and so on [8]. In addition, business areas also identify an architectural framework for integration, system design, and automation of the systems.

\section{EVALUATION OF COMMERCIAL BUSINESS SYSTEMS}

There are numerous existing commercial project management systems that have good functionality for the $\mathrm{A} / \mathrm{E} / \mathrm{C}$ project management. There is a many-tomany relationship between the business areas in Appendix B and the project management systems. Several project management systems can satisfy the needs of each business area and each project management system may satisfy the needs of many business areas. However, there is no project management system to fully support all business areas, since the project management systems are developed based on the needs of specific project management functions.

Table 2 contains correlation results between business areas and project management systems as provided by the software companies [11]. " $\sqrt{ }$ " means that the project management system supports the business area. Most systems are window-based and run on personal computers.

Table 2. Correlation between business areas and project management systems

\begin{tabular}{|c|c|c|c|c|c|c|c|c|c|c|c|}
\hline & 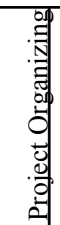 & 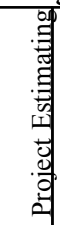 & $\begin{array}{l}\text { 音 } \\
\text { 氧 } \\
\text { 音 } \\
\text { 司 }\end{array}$ & 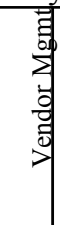 & 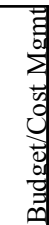 & 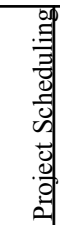 & 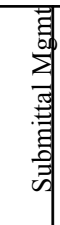 & 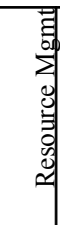 & 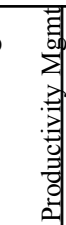 & 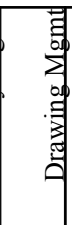 & 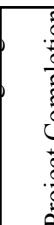 \\
\hline 1 & & & $\sqrt{ }$ & & & & & & & & \\
\hline 2 & & & $\sqrt{ }$ & $\sqrt{ }$ & $\sqrt{ }$ & & & & & & \\
\hline 3 & & 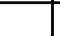 & $\sqrt{ }$ & $\sqrt{ }$ & $\sqrt{ }$ & $\sqrt{ }$ & & & $\sqrt{ }$ & & \\
\hline 4 & & & $\sqrt{ }$ & $\sqrt{ }$ & $\sqrt{ }$ & $\sqrt{ }$ & & $\sqrt{ }$ & $\sqrt{ }$ & & \\
\hline 5 & & & & & & & & & $\sqrt{ }$ & & \\
\hline 6 & & $\sqrt{ }$ & $\sqrt{ }$ & $\sqrt{ }$ & $\sqrt{ }$ & & $\sqrt{ }$ & & $\sqrt{ }$ & & \\
\hline 7 & & & $\sqrt{ }$ & $\sqrt{ }$ & $\sqrt{ }$ & & & & & & \\
\hline 8 & & & $\sqrt{ }$ & $\sqrt{ }$ & $\sqrt{ }$ & & & & & & \\
\hline 9 & & & $\sqrt{ }$ & $\sqrt{ }$ & $\sqrt{ }$ & & & & & & \\
\hline 10 & & $\sqrt{ }$ & $\sqrt{ }$ & $\sqrt{ }$ & $\sqrt{ }$ & & & & 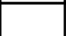 & & \\
\hline 11 & & & & & & $\sqrt{ }$ & $\sqrt{ }$ & & $\sqrt{ }$ & & \\
\hline 12 & & & $\sqrt{ }$ & $\sqrt{ }$ & $\sqrt{ }$ & & & & & & \\
\hline 13 & & $\sqrt{ }$ & $\sqrt{ }$ & $\sqrt{ }$ & $\sqrt{ }$ & & & & $\sqrt{ }$ & & \\
\hline 14 & & & & & & $\sqrt{ }$ & $\sqrt{ }$ & $\sqrt{ }$ & $\sqrt{ }$ & & \\
\hline 15 & $\sqrt{ }$ & & $\sqrt{ }$ & $\sqrt{ }$ & $\sqrt{ }$ & & & & & & \\
\hline 16 & & & $\sqrt{ }$ & $\sqrt{ }$ & & & & $\sqrt{ }$ & $\sqrt{ }$ & & \\
\hline 17 & & & $\sqrt{ }$ & $\sqrt{ }$ & $\sqrt{ }$ & $\sqrt{ }$ & & & & & \\
\hline 18 & & & $\sqrt{ }$ & $\sqrt{ }$ & $\sqrt{ }$ & $\sqrt{ }$ & $\sqrt{ }$ & & & & \\
\hline 19 & & & $\sqrt{ }$ & $\sqrt{ }$ & $\sqrt{ }$ & $\sqrt{ }$ & $\sqrt{ }$ & $\sqrt{ }$ & $\sqrt{ }$ & & \\
\hline 20 & & & $\sqrt{ }$ & $\sqrt{ }$ & $\sqrt{ }$ & $\sqrt{ }$ & $\sqrt{ }$ & $\sqrt{ }$ & $\sqrt{ }$ & & \\
\hline 21 & & & $\sqrt{ }$ & $\sqrt{ }$ & $\sqrt{ }$ & $\sqrt{ }$ & $\sqrt{ }$ & $\sqrt{ }$ & $\sqrt{ }$ & & \\
\hline 22 & & $\sqrt{ }$ & $\sqrt{ }$ & $\sqrt{ }$ & $\sqrt{ }$ & & & & & & \\
\hline 23 & & & $\sqrt{ }$ & $\sqrt{ }$ & $\sqrt{ }$ & & & & $\sqrt{ }$ & & \\
\hline 24 & & & & & & & & $\sqrt{ }$ & $\sqrt{ }$ & & \\
\hline 25 & & & $\sqrt{ }$ & $\sqrt{ }$ & 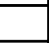 & 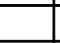 & $\sqrt{ }$ & $\sqrt{ }$ & $\sqrt{ }$ & $\sqrt{ }$ & \\
\hline 26 & & & $\sqrt{ }$ & $\sqrt{ }$ & $\sqrt{ }$ & $\sqrt{ }$ & $\sqrt{ }$ & $\sqrt{ }$ & $\sqrt{ }$ & & \\
\hline 27 & & & $\sqrt{ }$ & $\sqrt{ }$ & $\sqrt{ }$ & $\sqrt{ }$ & $\sqrt{ }$ & $\sqrt{ }$ & $\sqrt{ }$ & & \\
\hline 28 & & & $\sqrt{ }$ & $\sqrt{ }$ & & & & $\sqrt{ }$ & $\sqrt{ }$ & & \\
\hline 29 & & & $\sqrt{ }$ & $\sqrt{ }$ & & & & $\sqrt{ }$ & $\sqrt{ }$ & & \\
\hline 30 & & & $\sqrt{ }$ & $\sqrt{ }$ & $\sqrt{ }$ & & & & & & \\
\hline 31 & & & $\sqrt{ }$ & $\sqrt{ }$ & & & & & & & \\
\hline 32 & $\sqrt{ }$ & & $\sqrt{ }$ & $\sqrt{ }$ & $\sqrt{ }$ & $\sqrt{ }$ & $\sqrt{ }$ & $\sqrt{ }$ & $\sqrt{ }$ & & $\sqrt{ }$ \\
\hline 33 & & & $\sqrt{ }$ & $\sqrt{ }$ & $\sqrt{ }$ & & & $\sqrt{ }$ & $\sqrt{ }$ & & \\
\hline 34 & & & $\sqrt{ }$ & $\sqrt{ }$ & $\sqrt{ }$ & & & & & & \\
\hline
\end{tabular}

\section{SYSTEM INTEGRATION REQUIREMENTS}

In order to achieve integration between different business systems, several requirements should be considered.

At first, the business systems should have the ability to adapt to changing business needs. Executives want information systems that support the business as it changes. Databases and applications must be maintainable to quickly accommodate changes involving products, markets, and technologies. These changing needs can be considered as part of business strategies through EM as shown in this paper.

In addition, these changing needs require changing responsibility and role of each participant. For example, the owners are asking for analyses of budgets and actual expenditures to micromanage the day-to-day concerns of their jobs. They also call for 
some changes in methods and practices. Contractors should implement new processes, revamp inefficient ones, and automate others with minimal disruptions of ongoing business [12].

The data should be accessed in a useful format when and where needed [6]. Being able to obtain data when and where it is needed in a usable format is critical, since much of working time are used to handle data. Being in a useful format means that the data is readily interpretable into information and is not buried in a haystack of other and irrelevant data.

One approach, for example, can be thought with the integration of construction logistics, finances, and resource management needs. The system should match revenues to cost to allow for proper allocation of equipment overhead to jobs within schedules. Therefore, this system can protect huge capital investment in equipment through a comprehensive cost base for depreciation calculation [12].

The data should also be accurate and consistent. Executives want and expect the data that they receive to be accurate and consistent. The data must not only be correct within acceptable precision, but also consistent across the organization. For data to be properly interpreted and combined from all parts of the organization, a common vocabulary or data standard is needed. In addition, for accurate and consistent data, the level of detail of the data should be considered seriously.

The data must be shared across the enterprise to successfully meet business goals. Data must also be shared among departments and organization units, and further be centrally administered and coordinated. This statement, however, does not imply a single or centralized database. Rather, it is crucial that the data possess a common organization that eliminates redundancy and ensures the consistency of data wherever it might be.

For example, the operational data requires a normalized and relational structure to support data integration while controlling redundancy. Likewise, a normalized and relational structure is best when the data warehouse is designed to provide a source of integrated data to the business management and analysis processes [13]. To provide integration, several tools and processes should be employed in combination, for example, database systems and object-oriented programming.

\section{CONCLUSIONS}

The objective of this paper was to provide a conceptual process-data model of integrated information systems for $\mathrm{A} / \mathrm{E} / \mathrm{C}$ project through the IE. As the basis for system integration for $\mathrm{A} / \mathrm{E} / \mathrm{C}$ project, 11 business areas were suggested through interaction clustering.

It is concluded that no project management system support all business areas, since the project management systems were developed based on the specific project management functional needs. Those business systems need to be integrated system to provide effective project management.

To achieve system integration, changing business needs should be considered as part of business strategies through EM. The data should be processed in a useful format with high accuracy and consistency. The data must be also shared across the enterprise as well as among departments to successfully meet business goals.

\section{REFERENCES}

[1] Teicholz, P. and Fischer, M., "Strategy for Computer Integrated Construction Technology", Journal of Construction Engineering and Management, Vol. 120(1), pp.117-131, 1994.

[2] Abcede, A., "Software Packages Streamline Accounts Payable, Receivable," ConstrucTECH, Vol. 2(2), pp.36-38, 1999.

[3] Jung, Y. and Gibson, G.E., "Planning for Computer Integrated Construction," Journal of Computing in Civil Engineering, Vol. 13(4), pp.217225, 1999.

[4] Froese, T., "Models of Construction Process Information," Journal of Computing in Civil Engineering, Vol. 10(3), pp.183-193, 1996.

[5] Shahid, S. and Froese, T., "Project Management Information Control Systems," Canadian Journal of Civil Engineering, Vol. 25(4), pp.735-754, 1998.

[6] Spewak, S.H., Enterprise Architecture Planning: Developing a Blueprint for Data, Application, and Technology, QED Publishing Group, Boston/London/Toronto, 1992.

[7] Sirisuksakulchai, P., Information Engineering Approach for Defining An Integrated Project Management System, M.S. Independent Study, University of Wisconsin at Madison, Madison, WI, 1998.

[8] Martin, J., Information Engineering I \& II, Prentice-Hall Inc., NJ, 1990.

[9] IEF, A Guide to Information Engineering Using the IEF - Computer-Aided Planning, Analysis, and Design, Texas Instruments, 1990.

[10] Clough, R.H., Construction Project Management, Wiley-Interscience, NY, 1972.

[11] Novitski, B.J., “A/E/C Online”, A/E/C Systems, Dec, pp.6-81, 1997 
[12] Emond, M., "J.D. Edwards: Major leaguer in construction software," ConstrucTECH, 2(2), pp.3032,1999
[13] Moriarty, T. and Swenson, J., "The Data Requirements Framework," Database Programming \& Design, 11(4), pp.13-15, 1998

Appendix A. Process Data Flow Diagram of Cost/Resource Control

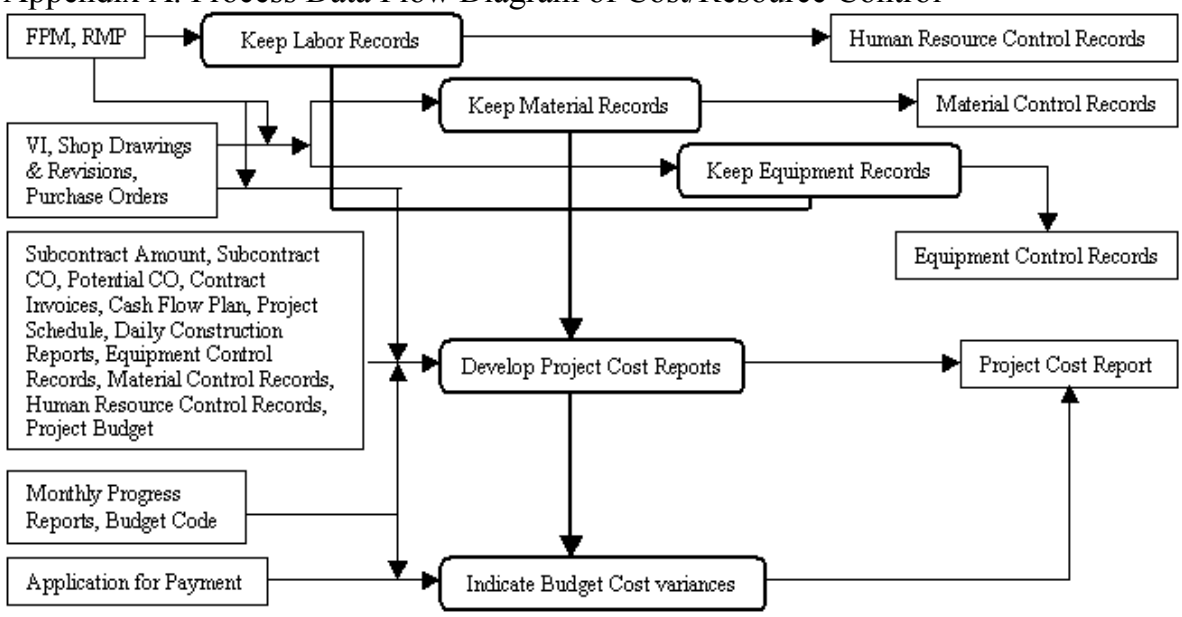

Appendix B Interaction Clustering

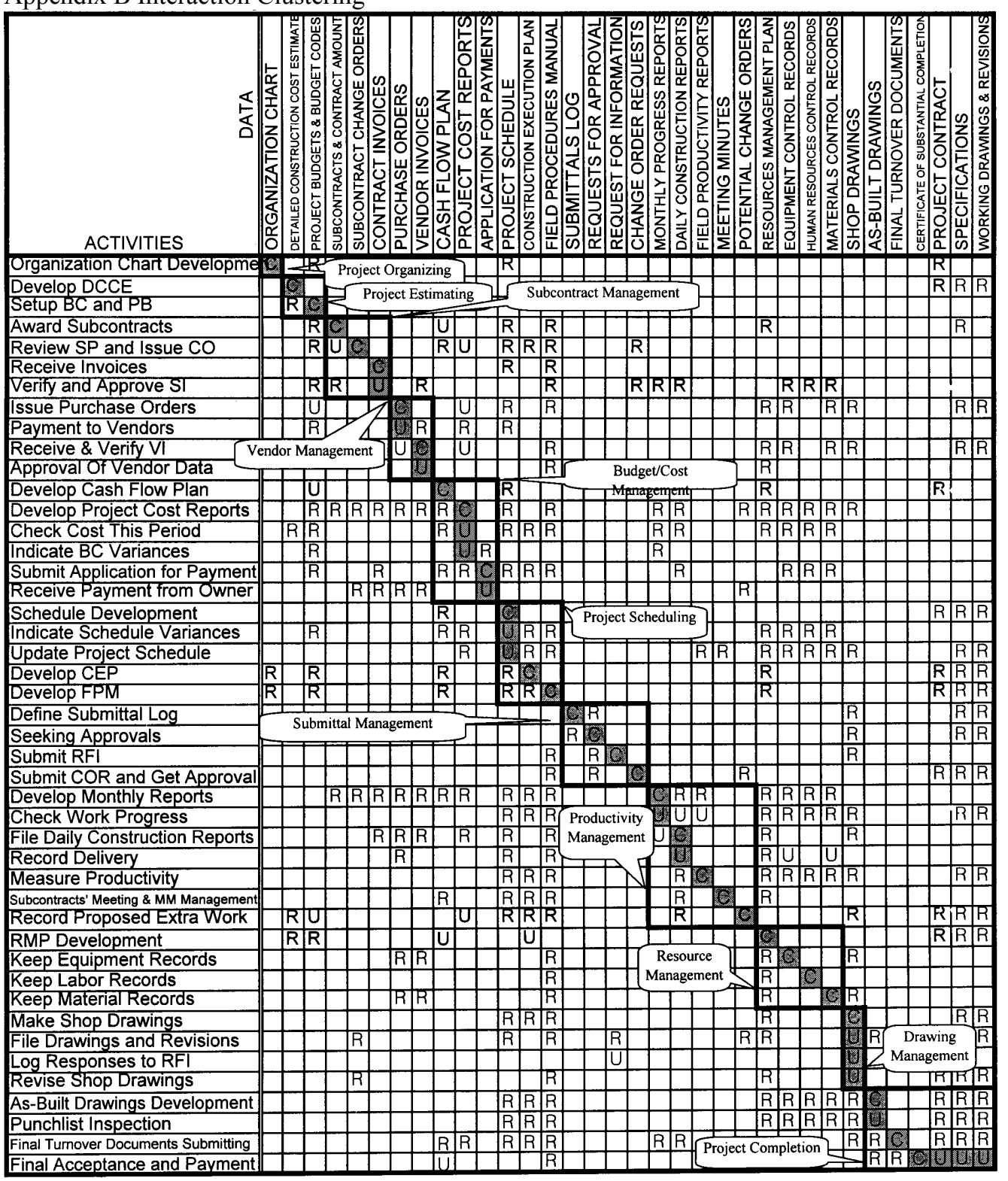

